\title{
The Effect of Healing Garden to Improve the Patients Healing: An Integrative Literature Review

\author{
https://doi.org/10.37719/jhcs.2020.v2i1.ra001
}

AGUSTINA SRI OKTRI HASTUTI, PhD NS ${ }^{1}$

https://orcid.org/0000-0003-3681-5837
JOSEPHINE D. LORICA, PhD, RN²

https://orcid.org/0000-0001-6660-6011

\author{
1Stikes Panti Rapih of Jogjakarta, Indonesia \\ 2St Paul University Philippines, Tuguegarao, Philippines \\ Corresponding author's email: oktri_hastuti@stikespantirapih.ac.id
}

\begin{abstract}
Background: Healing Garden (HG) is developed as one of the therapies that do not only help in the physical recovery of the patient but also helps to restore mental, social, and spiritual health. This paper aims to determine the benefit of Healing Garden for the patients in the hospital and to produce evidence that Healing Garden relates to the positive experiences of the patients and contributes to their feeling of well-being.
\end{abstract}

Method: The study utilized An Integrative Literature Review of Literatures through EBSCO, ProQuest, and Google Scholar. The articles searched were within 10 years, starting in 2007 until 2017 using the following terms for Boolean Search: "Healing Garden AND/OR Healing environment AND Hospital". Systematic search related to the topic was started on January 26, 2018 to February $6,2018$.

Results: The results of the study revealed seven themes which include 1). Nature provides positive energy for patients, 2) Healing Garden as a protected self-expression space, 3). Healing Garden has the potential to improve the quality of life for patients both physically and psychologically 4). Nature provides space to relate and socialize for patients and families, 5). Garden therapy as a bridge between the outside and spiritual world, 6) Nurses have an important role as a professional in creating a healing environment, and 7). The garden as a "Healing Garden" that should be visible, accessible, quiet, and comfortable.

Conclusion: The report of the study gives an overview that Healing Garden therapy has the various advantage that can effectively accelerate holistic healing. It is recommended to build healing gardens such as at the workplaces, schools, public areas, and other places where people can relax and 
unwind.

Keywords: Healing garden, holistic healing, hospital, patients

\section{Introduction}

$\mathrm{H}$

ealing Garden is an evolving concept that is gaining popularity today that involves the holistic healing for the patients in the hospital (Vapaa, 2002). Ulrich (1999) stated that the garden in

the hospital provides social support, a sense of control, physical movement and exercise, and other positive distractions. A garden is a plant-dominated environment with nature aspects such as plantations, flowers, waters, etc. (Say Jer et al., 2014). Many studies conducted by the architects show that being in a garden during certain times has a real impact on health recovery, both physically and psychologically. Ulrich (1984) studied patients who underwent gallbladder surgery and found that those who are admitted in a hospital whose room was facing the garden were discharged faster, given fewer doses of antibiotics and analgesics compared to patients admitted in a room facing the wall. Applying the concept of a healing environment during the treatment period was seen in the final condition of the patient's health, such as a reduction in the day of care, a reduced cost of care, decrease in the level of pain and stress reduction, and a positive mood (Dijkstra, 2009).

Diehl (2013, as cited by Fleming et al., 2013) stated that the garden as a "healing Garden" should have healing attributes. Upon consideration of the mentioned information, there is only a little health care literature that presents the benefits of a healing garden among patients in the hospital. Most of which pertain to the psychology and architectural design. Thus, this review aims to determine the benefit of Healing Garden for the patients in the hospital and to produce evidence that Healing Garden relates to the positive experiences of the patients and contributes to their feeling of wellbeing.

\section{Methodology}

\section{Research Design}

In this Integrative Literature Review (ILR), the methodology proposed by Ganong (1987) was utilized. The process begins with the formulation of the review purpose and questions, followed by delineating the inclusion and exclusion criteria, and conduct of the literature search. Afterward, it was followed by the adoption of a data collection tool, setting rules for the inference for data analysis and interpretation, and revising the data collection tool to fit the review purpose. Extracting relevant information from included articles, systematically analyzing the data, and then discussing and interpreting the data was then conducted. This ILR aimed to review literature from different disciplines that discussed the benefit of a healing garden for patients in the hospital. A literature search was 
performed through EBSCO, ProQuest, and Google Scholar library. The articles searched were within 10 years, starting in 2007 until 2017 with used the following terms for Boolean Search: "Healing Garden" AND/ OR "Healing environment" AND "Hospital". Systematic search related to the topic was started on January 26,2018 , to February 6,2018 . A total of 471 kinds of literature were initially searched and only eight (8) studies were chosen based on the inclusion and exclusion criteria. A matrix was used as a tool to extract the necessary data from the literature. After this, data were systematically analyzed, discussed, and interpreted.

\section{Inclusion and exclusion criteria}

Published articles that met the following criteria were chosen for inclusion: (1) written in English, (2) full-text articles, (3) participants are patients in the hospital, and (4) focused on the benefit of Healing Garden in Hospital. Titles were reviewed and when duplicates were identified only one study was included, thus, a total of 17 duplicates were initially excluded. After this, the titles and abstracts were reviewed, and 305 kinds of literature were found to have titles that have not matched the benefits of a healing garden and have participants other than patients in the hospital. Further, nine (9) kinds of literature were not written in English, and nine (9) were not research articles. Thus, a total of 18 articles were fully evaluated. Out of 18 articles, ten (10) were found to be irrelevant since it deals with studies related to the physical construction of the garden, hence, were excluded.

The PRISMA flow diagram (Figure 1) was used to determine the total number of works of literature that qualified as part of the review. The diagram was also used to monitor the screening and the identification of the eligible literature and to finalize the total number of the studies to be included in the review.

\section{Data extraction}

For each study, the language, author, year of publication, full-text availability, detail about the subject, and the method used were extracted. Then, the extracted data were written in the matrix and were revised based on the rules of inferences for the data analysis and interpretation.

\section{Results and Discussion}

Based on the eight (8) works of literature included in the study, a total of seven (7) themes were formulated. These include 1). Nature provides positive energy for patients, 2). Healing Garden as a protected self-expression space, 3). Healing Garden has the potential to improve the quality of life for patients both physically and psychologically 4). Nature provides space to relate and socialize for patients and families, 5). Garden therapy as a bridge between the outside and spiritual world, 6). Nurses have an important role as a professional in creating a healing environment, and 7). The garden as a "Healing Garden" that should be visible, accessible, quiet, and comfortable. The report 
of the study gives an overview that Healing Garden therapy has the various advantage that can effectively accelerate in holistic healing.

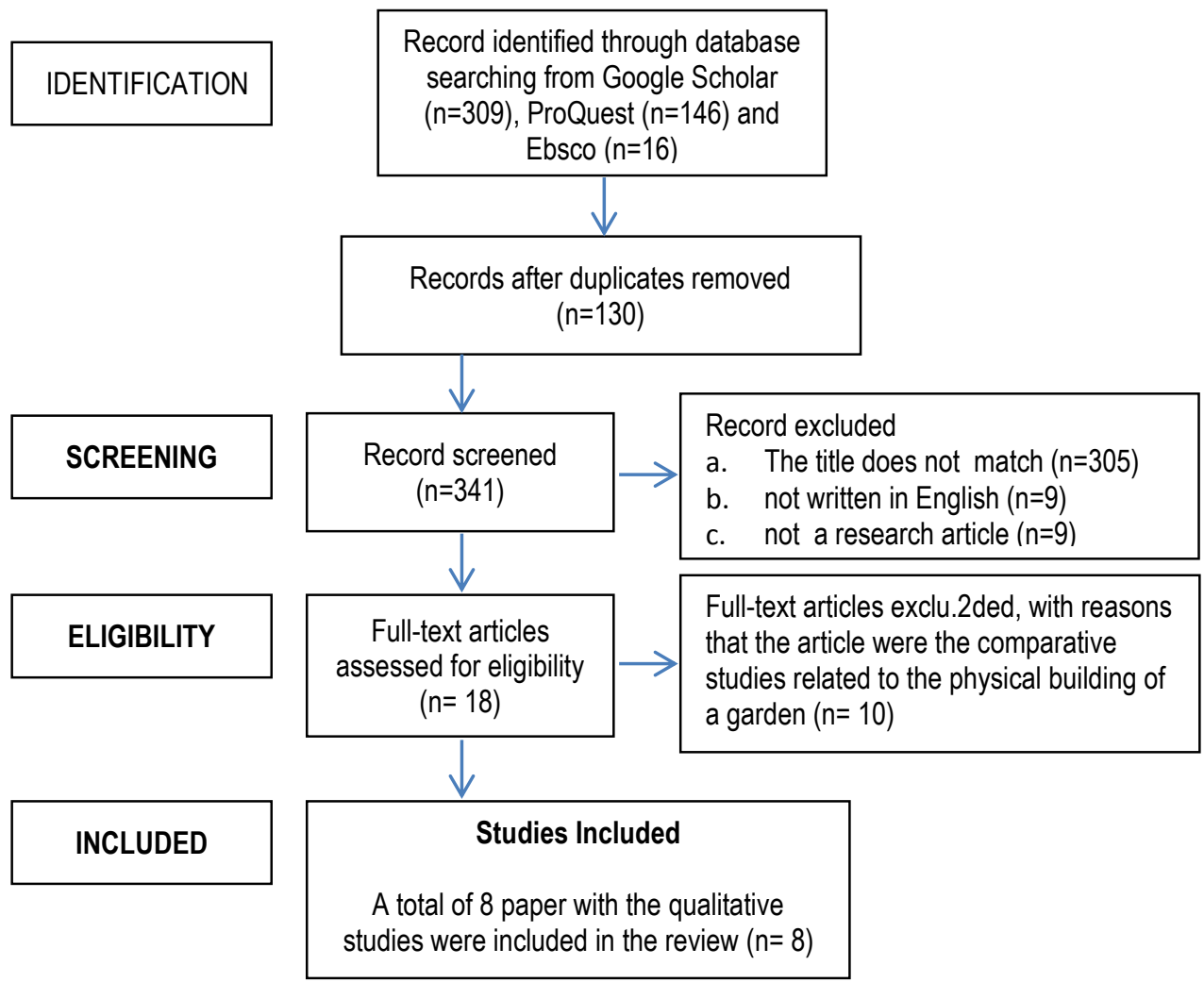

Figure 1. PRISMA Flowchart

\section{Nature provides positive energy for patients.}

Humans will feel healthier if they are happy and in turn, invite positive energy in a person. As it is well known that nature is the largest store of positive energy, being in the garden, will allow the patients to feel the flow of energy received. The beauty of the flowers, the sound of the wind, and the birds will make it fresh and give enthusiasm for the activity of the day. These findings confirm the opinion of Sevenedges (2014) which states that that nature gives place and pleasure also corroborates research results.

Marcus and Barnes (1995), that users of the garden have a positive change of mood after the time spent outdoors. Besides, this finding also supports Ulrich's state that garden allows accessing nature, and a place to reflect and reminisce in; a place of solitude, refuge, and familiarity, where it was reportedly possible to experience being present in the moment. That is why, there are 
patients who claim that a garden reflects life, as well as a life that is constantly changing but raises hope (Ivarsson \& Grahn, 2010).

\section{Healing Garden as a protected self-expressions space}

Humans can openly declare everything that is implied in their minds to others. Selfexpression is expressing everything that is in a person, both in the form of feelings, thoughts, ideas, and desires that are owned. A quiet garden can provide someone's space and peace. Those in the garden (patients, their families, and hospital staff) can shed all their hearts and ideas. The results of this study confirm the opinion of Ulrich (1999) which states that a garden can support "a sense of control" for its users. This is an important thing especially for patients because they are in the hospital and can "lose control" of themselves because they face stressful conditions due to various situations experienced.

This result is also under Ward's (2013) opinion That persons with a strong sense of control more likely believe that their actions are responsible for their experiences and expect that they can influence the likelihood of events in their life. Moreover, many studies have shown that a sense of control is an important factor affecting a person's ability to cope with stressful situations (Erickson, 2012). Control refers to people's real or perceived ability to determine what they do and to determine what others do to them. The same is confirmed by Waxman et al. (1984) that much of the stress of hospitalization has been linked to loss of control, for example, loss of privacy, inability to choose clothing, meals, and room temperature, and unfamiliarity with buildings., Furthermore, Equally important is the opinion of Ericson (2012) which states that stress related to lack of control has been shown to have many negative effects, including depression, decreased cognitive performance, increased blood pressure, increased levels of circulating stress hormones, and suppression of immune function.

\section{Healing Garden has the potential to improve the quality of life for patients both physically and psychologically}

This result is under the results of research by Hastuti (2017) that in the garden the patient feels healthier both physically and psychologically. The garden is a physical environment, providing an opportunity for patients. This result is confirmed by the opinion (Said et al., 2006) which states that especially for children, being in the garden can explore their physical abilities and cognitive skills. So, even in the hospital, patients may experience cognitive, affective, motoric, and social skills. This finding also supporting Marcus' (2007) statement that the meaning of the word "healing" in the healing garden is not meant to "cure" and will not cure hard diseases or any physical damages but it can reduce stress to a more balanced state. Also, according to Say Jer et al. (2014), it will build up selfconfidence, provide an environment for a therapeutic program with patients, and provide an alternative place for a visitor from hospital interior. 
Furthermore, Ivarsson and Grahn, (2010) argued that all gardens may have a therapeutic function, but the healing effect will be strengthened by the efforts or activities to support the recovery. In the same way, Weerasuriya et al. (2016) have specified that the psycho-physiological benefits of access in the garden reported were enhanced mood; reduced stress, agitation, distress, and anxiety; perceptions of enhanced safety and comfort, sensory stimulation, a sense of relaxation, rejuvenation, and hope. In the patient's view, nature also provided a great distraction when individuals were involved in overwhelming situations. Patients described nature as engrossing, and natural scenes as occasions to focus away from pain and discomfort (Barello et al., 2016).

These results are also supportive of Ulrich (1999) examines the health effects of the garden and suggests that there may be four potential benefits for health care facilities. According to Say Jer and Ibrahim (2014) these include stress reduction in patients, staff, and visitors, reduction in pain in patients, reduction in depression, a higher reported quality of life for chronic and severe illness, and finding better roads. Also, according to patients, observing beauty in nature offers comfort and pleasure (Ivarsson \& Grahn, 2010). Also, visual contact with nature can reduce stress and pain (Rowlands \& Noble, 2008). Children also exhibit supportive behaviors in their psycho-social and physical terms and provide the potential for better clinical outcomes (van der Riet et al., 2014). Furthermore, physical and psychological functions can be obtained during or after children participate in gardening activities (Said et al., 2006).

\section{Nature provides space to relate and socialize for patients and families}

In general, the definition of social support refers to the perceived emotional support or attention and physical assistance received by a person from another person (Erickson, 2012). This finding is by research conducted by Hastuti (2017) that while in the healing garden, patients feel they have found new friends and family. The social phenomenon in children is the transaction of children with their peers and caregivers (Said et al., 2006). Good social support can reduce stress and improve recovery (Say Jer et al., 2014; Rowlands \& Noble, 2008). Other than that, Said et al. (2016) state that peer relationship in children includes communication, negotiation, and learning to reduce conflicts.

Moreover, Rowlands \& Noble (2008) found that interacting with other patients for mutual support was important because this made them feel less isolated and can cope with their concerns better. Furthermore, Weerasuriya et al. (2016) stated that from a social perspective, the garden spaces provided an opportunity for more personalized interactions, a space to take visiting family and friends too, as well as spend time with colleagues. Also, access in the garden provided scope for enhanced interaction and conversation with others. Van der Riet et al. (2014) also stated that the benefit of Fairy Garden (FG) helped improve children 's development not just physically but socially and emotionally. Also, Ivarsson and Grahn (2010) stated that meeting others in the same situation, learning to appreciate their presence, and starting to open up is experienced by many as something very positive. 
Considering the above theme, a similar statement was also presented by Ulrich (1999), that a higher level of social support will improve stress reduction and recovery rate for various medical conditions than isolated ones. Therefore, Ulrich (1999) suggested that garden design should encourage people to gather together and experience social support (Erickson, 2012). Waters et al. (2008) described that "relational experiences are recognized and treated as a central energetic influence in creating a healing environment.

\section{Garden therapy as a bridge between the outside and spiritual world}

Schauer et al. (2016) defined spirituality as the breath or essence that infuses all life with meaning and that meaning is experienced through interconnectedness with nature, the earth, and the environment. While, Weerasuriya et al. (2016) described the experiences in nature as a connection to something "more powerful", "magical" or considered a "haven". As reported by Schauer et al. (2016), spirituality involves yearning for wholeness. Connectedness is an essential component of spirituality. Connection and relatedness may be experienced intrapersonal (connection to oneself), interpersonally (connection to others and the natural environment), and trans personally (sense of connection to the unseen, God, or something larger than the self) (Reed, 1992 as cited by Tranvag et al., 2016)

Furthermore, Schauer et al. (2016) found that immersion in nature impacts the human spirit such as connection, vibrancy, awe/presence, joy, gratitude, and compassion. The elements in nature commonly identified as earth, water, fire, wind, and space present in the gardens feature held multiple symbolic values. Especially, the larger trees were said to be symbolic of power, strength, wisdom, and regeneration while water fountains were symbolic of continuity. (Weerasuriya et al., 2016)

The Healing Garden provides a sense of safety, well-being, and show that life prevails even in the form of a plant or flower. Michaud (2003) reported that humans sometimes feel like they cannot move forward, or cannot change or evolve, but by connecting with nature maybe it can change, grow and reach great potential (Schauer et al., 2016). Also, apart from the power and strength that users drew from the garden experience, access to gardens was reported to have engendered a sense of tranquility and peace (Weerasuriya et al., 2016). These findings are also similar to research by Hastuti (2017) which states that when in a garden, patients feel a connection with the creator.

\section{Nurses have an important role as a professional in creating a healing environment}

A nurse is a person who has completed a program of basic, generalized nursing education and is authorized by the appropriate regulatory authority to practice nursing in his/her country. According to the American Nurses Association (ANA, 1980), nursing, as an integral part of the health care system, encompasses the promotion of health, prevention of illness, and care of physically ill, mentally ill, and disabled people of all ages, in all health care and other community settings. Within this broad spectrum of health care, the phenomena of particular concern to nurses are individual, 
family, and group "responses to actual or potential health problems"

Nightingale's view that nursing is the profession accountable for creating an environment that facilitates client healing. First and foremost, the nurse is responsible for providing a safe, comfortable, and supportive environment for the patient's healing. The nurse partners with the client to co-create the energetic capacity for making desired changes and expanding awareness that leads to healing (Waters et al., 2008). Historically, Nightingale suggested that nature was the best healer stating that the doctor and nurse can merely 'put the patients in the best condition for nature to act on them (Rowlands \& Noble, 2008).

Holistic care can be expressed as all forms of nursing practice whose goal is to help patient's comprehensive include physical, mental, social, and spiritual. Additionally, when asked patients opinions about the current environment, the majority of patients' first response was about the staff and in particular the nurses. They suggest that good staff (nurses) communication can reduce anxiety and improve overall outcomes for the patient (Rowlands \& Noble, 2008). The nursing profession is the powerhouse of a hospital and they accompany patients for 24 hours. In a healing process, nurses have an important role in holistic healing. Furthermore, Watson (1988) states that one of the causative factors that embodies caring for nurses is that nurses must create a healing environment at all levels.

The following indicators that the value of nurses and their roles were inferred from Watters's (2008) studied findings are: 1) Autonomy in making and implementing nursing practice decisions, 2) Support for individualizing client care, 3) Time and resources to support healing practices, 4) Recognition of the essential relationship between nurse self-healing and client healing, 5) Differentiation between technical and professional practice, and 6) Strong nursing presence throughout the organization.

In the hospital, nurses are responsible for integrating a curative aspect of care to a health professional (doctor, nutrition, pharmacist, etc.) to cure the patient, not only the physical but also the psychological, social, and spiritual of the patients. (Waters et al., 2008)

\section{The garden as a "Healing Garden" that should be visible, accessible, quiet, and comfortable}

According to the American Horticultural Therapy Association (2007), the garden is an environment dominated by plants with natural aspects such as plantations, flowers, water, etc. The garden is designed to relax and unwind for the user. People who use the garden to just look around, sit around, walk, rest, pray or meditate, read, exercise lightly, play, and receive a therapeutic program. Thus, one thing that needs to be considered in designing the garden is its ability to provide opportunities to move and exercise. Sport is a combination of physical and psychological benefits (Brannon \& Feist, 1997; Koniak-Griffin, 1994). The second function is a setting that allows children to play and the third function is a setting for walking contemplatively (eg, Labirin) and for users to walk or jog. The last function is the arrangement with approval for post-operation training. 
This finding is the same as Marcus (1999) who stated that the garden around the hospital can be used as a healing garden for patients, to develop its full potential the following qualities such as visibility, accessibility, familiarity, quietness, comfortability, and shaped art are necessary. Furthermore, Marcus (2007) described that there are potential activities for users in the garden which is viewing, sitting, walking, resting, meditation praying, receiving the therapeutic program, reading, playing and sporting

\section{Conclusion}

Based on the results of research on healing garden from previous researchers, it is important to understand that Healing garden therapy is very useful for hospitalized patients because it can affect to calm the mind, awaken the senses, reduced stress, and assist the user to master their inner healing resources. Also, nurses have a big role in creating a healing environment for patients. A Healing Garden is a garden that is easy to access, has privacy, and comfortable.

\section{Limitation of the Study}

Although the creation of a healing environment is an often-cited goal of nursing, there is no formal professional consensus on what is meant by a healing environment. Not many studies have been conducted by health care providers (nurses) regarding the benefits of Healing Garden in supporting the healing of clients/patients. Thus, the professional literature on this subject is ambiguous and does not yet provide clear directions for practice.

\section{Recommendation}

Based on the evidence that has been found that healing gardens in hospitals are useful for restoring patients' health conditions both physical and psychological, it is recommended to build healing gardens in public places such as workplaces (offices), schools, public areas, and other places where people can relax and unwind.

\section{Acknowledgement}

This paper has been produced as part of the requirements for the Doctor of Philosophy in Nursing Science at St. Paul University Philippines and was finalized with the editing assistance provided by the University. 


\begin{tabular}{|c|c|c|}
\hline No & Authors, year & Purpose of the Study \\
\hline 1 & $\begin{array}{l}\text { Barello, Graffigna, } \\
\text { Menichetti, Sozzi, } \\
\text { Savarese, Claudio, } \\
\text { Corbo (2016). }\end{array}$ & $\begin{array}{l}\text { This study aimed to } \\
\text { explore the post-stroke } \\
\text { patients' experience of } \\
\text { person-centered } \\
\text { therapeutic gardening as } \\
\text { part of their rehabilitation } \\
\text { intervention by 1) } \\
\text { deepening our } \\
\text { comprehension of the } \\
\text { psycho-social experience } \\
\text { of post-stroke patients } \\
\text { regarding their } \\
\text { involvement in therapeutic } \\
\text { gardening, and 2) } \\
\text { exploring whether } \\
\text { therapeutic gardening is } \\
\text { perceived by patients as } \\
\text { an opportunity to foster } \\
\text { their engagement toward } \\
\text { rehabilitation and self- } \\
\text { care. }\end{array}$ \\
\hline
\end{tabular}

2 Ivarsson, \& Grahn (2010).

3 Van der Riet, Jitsacorn, Junlapeeya, \& Dedkhard (2014).
The purpose of this study was providing designers of therapeutic settings with more substantiated information to guide their design choices

This paper aimed to report on the experiences of nurses of sick children who have participated in formal and informal activities in a healing haven environment called a 'Fairy Garden'
The design in this research is phenomenology because the object of this study is to broaden our knowledge of how a therapeutic landscape is used and experienced by its patients

This was a qualitative study using narrative inquiry (NI). Dysvik et al. (2013) argue that narrative has different meanings, and over the years, researchers have had different approaches to narrative.

\section{Participants}

The participant in this research were 22 Italian participants, all of whom had been patients who have been involved in therapeutic gardening activities.

They were selected from a list of patients taking part in a rehabilitation program for post-stroke patients at the hospital.

The sampling strategy used in this study was that of purposive sampling.

In purposive sampling, participants are individually selected according to their knowledge of the phenomenon.

The criteria inclusion criteria were: adults aged 50 or more; confirmed diagnosis of cerebral stroke, either ischemic or hemorrhagic; first acute event; being still physically active and interested in engaging in gardening sessions; Mini-Mental State Exam score $>$ 24/30; Cumulative Index Rating Scale $<5$; ability to converse in Italian; willingness to participate to the study; and cognitive capabilities and medical condition conducive to participation.

While, the exclusion criteria included: patients with psychiatric disorders and focal neuropsychological deficit (eg. aphasia, neglect); individuals who could not speak; confused individuals; patients who refused to sign informed consent.

The number of a participant in this study are ten patients with stress-related diseases and they are in the rehabilitation program with natureassisted therapy. This study located in the healing garden, Sweden.

In the Study, each patient has spent in the garden therapy differs from six weeks to spread out over eight months

A purposive sample of eight nurse participants was interviewed in three focus groups $(n=8)$. The inclusion criteria were 1) Nurses working in the two children's wards.

2) Nurse administrators working at the hospital with involvement in the children's wards. 


\section{No Authors, year Purpose of the Study Research Design Participants}

Initially, one focus group interview was with two head nurses, a second interview was with three ward nurses, and a third interview group was with three nurse administrators. In attendance were the principal researcher, the Thai language translator (who was part of the research team), and the nurses.

For each focus group interview, there were open-ended questions, with several key questions aiming to generate reflection and discussion.

4 Rowlands \& Noble (2008).

5 Said, Sarofil, \& Bakar (2006).

6 Say Jer, \& Ibrahim (2014).

7 Waters, Kritek, Cowling, Peloquin, Fenton, \& Hill (2008).
This study aimed to explore the views of patients with advanced cancer on the effect the ward environment has on their overall well-being

This study examines a phenomenological approach to elicit the behavioral responses of pediatric patients, aged 612 , who are experiencing a hospital garden.

The purpose of the paper was to find the elements of healing gardens and its healing factors in the existing garden design

The purpose of this study was to identify and describe characteristics of a healing environment from a nursing perspective
A phenomenological approach was chosen to describe the lived experiences of the patients as they see it and interpret the data to identify core themes.

A semi-structured interview format was formulated based on the findings from pilot interviews with four patients.

The interview format focused on the patient's experiences of the hospital ward and facilities, and how they felt the environment affected their mood and quality of life during their hospital stay.

This study was the phenomenological approach

The main methods of data collection were observation and informal interviews with the patrons.

This qualitative study was conducted using an interpretive descriptive method consistent with a naturalistic inquiry model
The participants were 12 patients. The sampling was purposive sampling with inclusion/exclusion criteria.

Participants were representatives of the oncology center SPCU with respect to sex, age, disease, and nursing needs dependency

The participant of this study was children patients aged 6-12, who are experiencing a hospital garden.

The participants were the patients and visitors in the garden

The participant in this study was 9 expert nurses and the sampling with purposive sampling who practice within the conceptual framework of Rogers' The science of Unitary Human Beings. This study, that to increase the probability of selecting good informants, 


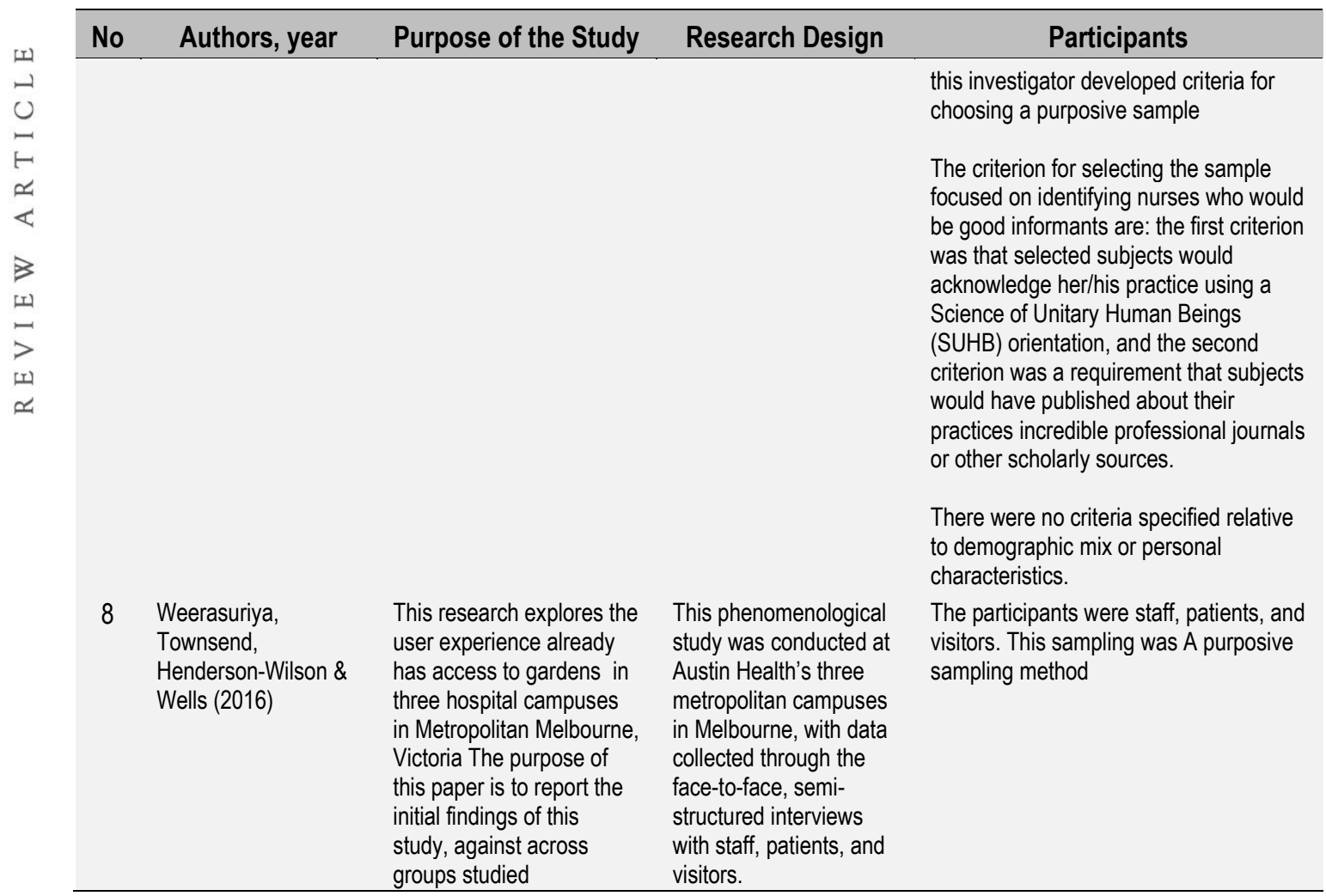

\section{References}

Barello, S., Graffigna, G., Menichetti, J., Sozzi, M., Savarese, M., Bosio, A. C., Corbo, M. (2016).The Value of a Therapeutic Gardening Intervention for Post-Stroke Patients' Engagement During Rehabilitation: An Exploratory Qualitative Study. Journal of Participatory Medicine, 8, 1-9

Crosetti, M. \& Crosetti, M.D.O (2012). An integrative review of nursing research: Scientific rigour required. Nursing Brazilian Journal, 33(2), 12-13.

Dietz, L. (n.d.). Healing Spaces: Gardening Activities for Stress-Reduction. http://soundideas.pugetsound.edu/ cgi/viewcontent.cgi?article=1050\&context=ms_occ_therapy

Dijkstra, K. (2009). Understanding healing environments : effects of physical environmental stimuli on patients' health and well-being. Enschede: University of Twente. https://doi.org/10.3990/1.9789036527958

Erickson, M. S. (2012). Restorative garden design: Enhancing wellness through healing spaces. JAD Art Design Journal, 2, 89-102.

Fleming, L., Morrison, J., \& Oh, D. (2013). Healing Gardens Therapeutic Gardens, (1984), 1-2.

Ganong, L.H. (1987). Integrative reviews of nursing research. Research in Nursing \& Health, 10(1), 1-11. https://doi.org/10.1002/nur.4770100103

Goodson, P., \& Ulrich, R. (2008). Effect of healing garden use on stress experienced by parents of patients in a pediatric hospital. http://oaktrust.library.tamu.edu/bitstream/handle/1969.1/ETD-TAMU-2008-058/Toone_Thesis.pdf 
Hastuti, S., O. (2017). Healing Garden Therapy is a Holistic Healing for the Patients. Journal IRC, 4. St. Paul University Philippines

Ivarsson, C. T., \& Grahn, P. (2010). Patients' experiences and use of a therapeutic garden: from a designer's perspective. Schweizerische Swiss Journal of Forestry, 161(3), 104-113. https://doi.org/10.3188/szf.2010.0104

Marcus, C. C. (2007). Healing Gardens in Hospitals. Design and Health, 1(1), 1-27.

Moher, D., Liberati, A., Tetzlaff, J., Altman, D.G. (2009) Preferred reporting items for systematic reviews and meta analyses: the PRISMA statement. Open Medicine, 3:e123-e130

Pouya, S., Bayramoğlu, E., Demirel, Ö., Teknik Üniversitesi, K., Fakültesi, O., Mimarlığı Bölümü, P., \& Yazar, S. (2016). Restorative Garden as a Useful Way to Relieve Stress in Megacities, a Case Study in Istanbu. Inönü University Journal of Art and Design, 6(13), 355-369. https://doi.org/10.16950/iüstd.55348

van Der Riet, P., Jitsacorn, C., Junlapeeya, P., \& Dedkhard, S. (2014). Nurses ' stories of a "Fairy Garden " healing haven for sick children. Journal of Clinical Nursing, 23(23-24), 3544-3554. https://doi.org/10.1111/jocn.12637

Rowlands, J., \& Noble, S. (2008). How does the environment impact on the quality of life of advanced cancer patients? A qualitative study with implications for ward design. Palliative Medicine, 22(6), 768-774. https://doi.org/10.1177/0269216308093839

Said, I., Sarofil, M., \& Bakar, A. (2006). Phenomenological Approach in Determining Responses of Hospitalised Children Experiencing a Garden. Jurnal Alam Bina, 8(1). https://core.ac.uk/download/ pdf/11782000.pdf

Say Jer, O., \& Ibrahim, F. (2014). Enhancement of Space Environment Via Healing Garden. American Transactions on Engineering \& Applied Sciences, 1(1), 281-298.

Schauer, Becky; Koch, Kishori; Lemieux, Laura; and Willey, Kendra. (2016). How Immersion in Nature Impacts the Human Spirit: A Phenomenological Study. St. Catherine University repository website: https://sophia.stkate.edu/ma_hhs/8

Ward, M. M. (2013). Sense of control and self-reported health in a population-based sample of older Americans: assessment of potential confounding by affect, personality, and social support. International Journal of Behavioral Medicine, 20(1), 140-7. https://doi.org/10.1007/s12529-011-9218-x

Waters, P. J., Kritek, P. B., Cowling lii, R., Peloquin, S. M., Fenton, M., \& Hill, A. (2008). Characteristics of a healing environment as described by expert nurses who practice within the conceptual framework of rogers' science of unitary human beings: a qualitative study. http://citeseerx.ist.psu.edu/viewdoc/ download?doi=10.1.1.464.1511\&rep=rep1\&type=pdf

Weerasuriya, R., Townsend, M., Henderson-Wilson, C., \& Wells, S. (2016). Exploring the health and well-being experiences in accessing gardens within a health care setting in Australia: the preliminary findings. Acta Horticulturae, (1121), 59-68. https://doi.org/10.17660/ActaHortic.2016.1121.10 
Agustina Sri Oktri Hastuti, PhD NS, is a lecturer at Stikes Panti Rapih Yogyakarta. Before becoming a lecturer, she was a nurse who worked at a private hospital in Yogyakarta. She received the Bachelor degree of Public Health from Universitas Diponegoro in 1999 and received the Master degree of Nursing Management from Universitas Indonesia in 2009, respectively. Recently, she received her PhD degree from St Paul University, Philippines in 2019. Her Dissertation was about the "Development of Caring Healing Garden Therapy Program for Hospitals". She also involved in qualitative researchers community and did several researches with healing garden as the main topic.

Josephine D. Daquioag-Lorica, PhD, RN, is currently a faculty of the School of Nursing and Allied Health Sciences. She has been in the University since October 1992. She finished her Bachelor of Science in Nursing in 1991, Master of Science in Nursing in 1995 and Doctor in Public Administration in 2003 all in SPUP. And at present she is enrolled in the Doctor of Philosophy in Nursing Science in the same institution. Her research interests are in nursing research and provision of nursing care across populations. She has taught research for the past 10 years and have assisted nurses and other allied health professionals in coming up with their research papers. 